\title{
Surgical ablation as treatment for the elimination of atrial fibrillation: A meta-analysis
}

Scott D. Barnett, PhD, and Niv Ad, MD

Earn CME credits at http:// cme.ctsnetjournals.org.

See related editorial on page 949.
From Inova Heart and Vascular Institute, Falls Church, Va.

Received for publication June 14, 2005; revisions received Oct 12, 2005; accepted for publication Oct 25, 2005.

Address for reprints: Scott D. Barnett, PhD, Inova Heart and Vascular Institute, 3300 Gallows Rd, Falls Church, VA 22042 (Email: scott.barnett@inova.com).

J Thorac Cardiovasc Surg 2006;131:1029-35 0022-5223/ $\$ 32.00$

Copyright $(\subset) 2006$ by The American Association for Thoracic Surgery

doi:10.1016/j.jtcvs.2005.10.020
Objective: The maze procedure is recognized as the most effective surgical treatment of atrial fibrillation. In the last few years, new surgical ablation techniques were developed involving the left atrium only and modifications of the maze procedure in ablating both atria. For this study, we evaluated the evidence regarding the effectiveness of the surgical ablation procedures (biatrial and left atrial) in reducing postoperative atrial fibrillation and subsequent survival.

Methods: MEDLINE was searched for English-language studies using the terms "maze," "atrial fibrillation," and "surgical treatment" for 1995 through August 2005. Primary outcomes of interest were postoperative survival and postoperative freedom from atrial fibrillation. Survival data were collected at 1-, 2-, and 3-year intervals. Freedom from atrial fibrillation was collected at 3 months and at 1-, 2-, and 3-year intervals.

Results: Sixty-nine studies were included in this analysis. Five thousand eight hundred eighty-five total patients were involved. Patients undergoing surgical ablation (range, 90.4-85.4) demonstrated significantly greater rates of freedom from atrial fibrillation compared with those seen in control patients (range, 47.2-60.9). Survival rates among patients with biatrial surgical procedures (range, 94.9-92.8) were similar to those who had left atrial procedures only (range, 93.9-89.4). However, patients undergoing biatrial ablation (range, 92.0-87.1 vs 86.1-73.4) demonstrated superior freedom from atrial fibrillation at all time points.

Conclusion: Biatrial ablation surgical procedures were more effective in controlling atrial fibrillation than procedures confined to the left atrium. To encourage the use of future meta-analysis within the surgical literature, we suggest the more frequent reporting of either through Kaplan-Meier survival analyses and the reporting of rates for specific time intervals.

$\mathrm{T}$ The maze procedure is recognized as the most effective surgical treatment of atrial fibrillation (AF). Introduced in 1987 by J. L. Cox as a stand-alone procedure, the maze procedure has undergone 4 iterations, with each successfully replacing the previous one.

To our knowledge, there have been no systematic reviews or meta-analyses to estimate and compare the efficacy of the maze procedure and any other biatrial surgical procedure with that of procedures limited to the left atrium in the elimination of AF. The goal of this study is to assess the evidence regarding the effectiveness of the different surgical ablation techniques in eliminating postoperative recurrent $\mathrm{AF}$. In addition, we report postoperative survival rates for 1, 2, and 3 years.

\section{Methods}

\section{Search Strategy}

We searched MEDLINE for studies in English using the terms "maze," "atrial fibrillation," and "surgical treatment" for the period of 1995 through March 2005. We eliminated any case 


\section{Abbreviations and Acronyms}

$\mathrm{AF}=$ atrial fibrillation

reports or articles focusing on electronic advances in the surgical treatment of AF. Four studies were eliminated because they represented the same patient group. Studies were then reviewed a final time by each author to ensure the search criteria were met and desired clinical data were included. ${ }^{1-69}$

\section{Statistical Methods}

Each author then reviewed each report to dichotomize every study into temporal categories of "retrospective" or "prospective" and to assign study sample sizes to one of 3 size categories on the basis of the sample of surgical patients in each study: small $(<50)$, medium (51-100), or large $(>100)$. The individual author results were then compared, and differences in interpretation were resolved. Included studies reflected surgeon preference for the use of different procedures: the use of some studies using the standard maze procedure lesion set and others using different protocols for biatrial and left atrial lesion sets only. Thus we defined included surgical ablation procedures as either biatrial or left atrial procedures only.

The primary outcomes of interest were postoperative survival and postoperative freedom from AF. Survival data were collected at 1-, 2-, and 3-year intervals. Freedom from AF was collected at 3 months and at 1-, 2-, and 3-year intervals. In the event that a study involved multiple control groups, control group survival and freedom from AF estimates were combined into one control group by using weighted averages, with the respective control group sample sizes serving as the weights.

Effect sizes for all end points were calculated by using the Cohen d statistic. ${ }^{70}$ Variance estimates for all end points were calculated by using the method of Hunter and Schmidt. ${ }^{71}$ Weighted postoperative survival and freedom from AF estimates were analyzed, with the respective study surgical group or control group sample sizes used as the weights. The Student $t$ test was used to test for statistical significance. All statistical analyses were conducted with SAS (version 8.12; SAS, Cary, NC) software.

\section{Results}

\section{Studies}

Sixty-nine studies were included in this analysis. Biatrial surgical ablation procedures accounted for $67 \%$ of all studies, and $75 \%$ were retrospective in nature. Small studies $(<50$ subjects) comprised almost one half of all studies (42\%). Only 14 (19\%) studies involved control groups. Average patient follow-up was 22.9 months. Primary indication for surgical intervention was prolonged AF, usually defined as "chronic," generally presented in tabular format in the Results section or defined earlier as "chronic" or "persistent" AF lasting more than 6 or 12 months. Electrocardiography, Holter monitoring, echocardiography, or combinations of these were primarily used to define postoperative freedom from AF. Several reports relied on pa-
TABLE 1. Average sample size

\begin{tabular}{lcccr}
\hline \multicolumn{1}{c}{ Parameter } & $\begin{array}{c}\text { No. of } \\
\text { studies }\end{array}$ & $\begin{array}{c}\text { Mean no. of } \\
\text { patients }\end{array}$ & $\begin{array}{c}\text { Standard } \\
\text { deviation }\end{array}$ & Range \\
\hline Total no. of subjects & 69 & 85.3 & 62.1 & $10-276$ \\
Surgical subjects only & 69 & 74.9 & 59.8 & $5-276$ \\
Control subjects only & 14 & 51.3 & 57.2 & $10-227$ \\
Biatrial sample size & 47 & 73.3 & 61.3 & $5-276$ \\
Left atrial sample size & 24 & 67.3 & 58.2 & $13-234$ \\
\hline
\end{tabular}

tient self-report during follow-up, but electrocardiographic confirmation was then obtained. Freedom from AF end points was primarily defined as a return to sinus rhythm.

\section{Samples Size}

Sample sizes for selected studies averaged 85.3 (74.9 for subjects undergoing surgical ablation and 51.3 for control subjects, Table 1). Studies with the biatrial ablation procedure averaged 73.3 subjects, and studies with left atrial procedures averaged 67.3 subjects. Sample sizes for which a control group was involved generally included more control subjects compared with surgical patients (average, 51.3 [range, 10-227] vs 37.1 [range, 5-103]).

When stratified by lesion, studies involved more patients undergoing biatrial ablation $(88.0 \pm 60.1)$ compared with patients undergoing left atrial ablation $(79.9 \pm 67.1$, Table $2)$. When stratified by temporal score, prospective studies enrolled fewer total subjects $(57.8 \pm 40.4)$ and almost one half as many surgical patients $(45.0 \pm 32.7)$ compared with retrospective studies $(94.3 \pm 65.6$ and $84.7 \pm 63.5$, respectively; Table 2).

\section{Patient Survival and Freedom from AF, All Patients}

Patients undergoing surgical ablation demonstrated similar survival rates compared with those of control patients (Table 3). At 1, 2, and 3 years, control subjects demonstrated a $3 \%$ improvement in survival. However, at 3 months and 1 , 2 , and 3 years, patients undergoing surgical ablation (range, 90.4\%-85.4\%) demonstrated significantly greater rates of freedom from $\mathrm{AF}$ compared with those seen in control subjects (range, 47.2\%-60.9\%). With the exception of the 3-year end point, surgical patients nearly doubled the freedom from $\mathrm{AF}$ rate compared with that seen in control subjects.

\section{Patient Survival and Freedom From AF by Lesion}

When stratified by lesion (biatrial lesions vs left atrial lesions only), survival rates among biatrial surgical patients (range, 94.9\%-92.8\%) were similar to those among left atrial surgical patients (range, 93.9\%-89.4\%; Table 4). Biatrial surgical patients (range, 92.0\%-87.1\%) demonstrated superior freedom from $\mathrm{AF}$ at all time points compared with left atrial surgical patients (range, 86.1\%-73.4\%). 
TABLE 2. Average sample size by lesion and temporal score

\begin{tabular}{|c|c|c|c|c|c|c|c|}
\hline & \multicolumn{3}{|c|}{ Biatrial } & \multicolumn{3}{|c|}{ Left atrial } & \multirow[b]{2}{*}{$P$ value } \\
\hline & $\begin{array}{l}\text { No. of } \\
\text { studies }\end{array}$ & Mean \pm SD & Range & $\begin{array}{l}\text { No. of } \\
\text { studies }\end{array}$ & Mean \pm SD & Range & \\
\hline Total subjects & 46 & $88.0 \pm 60.1$ & $10-276$ & 23 & $79.9 \pm 67.1$ & $13-234$ & .312 \\
\hline Surgical subjects & 46 & $79.0 \pm 59.6$ & $10-276$ & 23 & $66.6 \pm 60.5$ & $5-234$ & .210 \\
\hline Control subjects & 10 & $41.3 \pm 31.1$ & $10-97$ & 4 & $76.3 \pm 100.6$ & $19-227$ & .247 \\
\hline
\end{tabular}

Prospective

$\begin{array}{lrr}\text { Total subjects } & 17 & 57.8 \pm 40.4 \\ \text { Surgical subjects } & 17 & 45.0 \pm 32.7 \\ \text { Control subjects } & 7 & 31.0 \pm 26.2 \\ \text { BLA sample size } & 13 & 45.8 \pm 35.1 \\ \text { LA sample size } & 5 & 33.8 \pm 20.5 \\ \text { SD, Standard deviation; BLA, bilateral; } L A \text {, left atrial. } \\ \\ \text { Patient Survival and Freedom From AF by } \\ \text { Temporal Score }\end{array}$

When stratified by temporal score, both prospective and retrospective studies demonstrated similar survival rates at 1, 2, and 3 years (Table 5), with prospective studies slightly better (range of $95.2 \%-96.1 \%$ vs range of $94.3 \%-91.9 \%$ ). Retrospective studies, however, demonstrated increased rates of freedom from AF (range of $91.4 \%-87.3 \%$ vs range of $86.3 \%-79.4 \%$ ).

\section{Discussion}

The use of meta-analyses to summarize research is not a novel approach but is still a vastly underused research tool. Ideally, investigators would pool individual data from multiple studies under various hypotheses either similar or identical to those of their original respective study. Usually, however, results from published reports are abstracted through the use of statistics on the basis of sampling methods. ${ }^{70,71}$ Results are pooled, and effect sizes can then be generated as if all studies were generated from one large hypothetical patient population, with each study acting as a unique sample from that hypothetical population. The literature addressing the surgical treatment for AF now has dozens of studies on various populations from various highly regarded surgical groups, all producing excellent results. In this report we present the results of what we believe to be the first large-scale meta-analysis designed to evaluate the efficacy of surgical ablation as a treatment for the elimination of AF.

Our results suggest that both surgical groups with and without ablation experience nearly identical postoperative survival rates and superior freedom from $\mathrm{AF}$ rates at 3 months and 1, 2, and 3 years. Furthermore, among surgical patients, biatrial ablation procedures were similar to left atrial ablation-only procedures in postoperative survival and superior in freedom from AF rates. The higher success rate in ablating $\mathrm{AF}$ by applying the maze procedure or any other biatrial surgical modification is not surprising. Review of the current literature that discusses the electrophysiology of AF reveals that there are quite a few different mechanism suggested, from simple mechanisms pointing to the pulmo-

TABLE 3. Average weighted reported postoperative survival and freedom from recurrent atrial fibrillation, all patients

\begin{tabular}{|c|c|c|c|c|c|c|c|}
\hline & \multicolumn{3}{|c|}{ Surgical subjects } & \multicolumn{3}{|c|}{ Control subjects } & \multirow[b]{2}{*}{$P$ value } \\
\hline & $\begin{array}{c}\text { No. of } \\
\text { studies }\end{array}$ & $\begin{array}{c}\text { Total } \\
\text { sample } \\
\text { size }\end{array}$ & Mean $\pm S D^{*}$ & $\begin{array}{l}\text { No. of } \\
\text { studies }\end{array}$ & $\begin{array}{c}\text { Total } \\
\text { sample size }\end{array}$ & Mean \pm SD* & \\
\hline 1-y survival & 52 & 3841 & $94.5 \pm 0.0$ & 11 & 429 & $97.8 \pm 0.0$ & .001 \\
\hline 2-y survival & 18 & 1313 & $94.1 \pm 0.0$ & 5 & 299 & $97.7 \pm 0.0$ & .001 \\
\hline 3-y survival & 17 & 1338 & $92.5 \pm 0.0$ & 6 & 334 & $95.1 \pm 0.0$ & .001 \\
\hline 3-mo freedom from AF & 39 & 2742 & $90.4 \pm 6.0$ & 7 & 236 & $47.2 \pm 17.2$ & .001 \\
\hline 1-y freedom from AF & 37 & 3225 & $84.5 \pm 10.3$ & 10 & 312 & $30.8 \pm 19.6$ & .001 \\
\hline 2-y freedom from $A F$ & 21 & 1739 & $84.3 \pm 5.9$ & 5 & 181 & $39.7 \pm 21.6$ & .001 \\
\hline $3-y$ freedom from $A F$ & 18 & 1801 & $85.4 \pm 5.3$ & 6 & 514 & $60.9 \pm 31.0$ & .013 \\
\hline
\end{tabular}

$S D$, Standard deviation; $A F$, atrial fibrillation. *Sample weighted mean and corrected standard deviation. 
TABLE 4. Average weighted reported postoperative survival and freedom from recurrent atrial fibrillation by lesion

\begin{tabular}{|c|c|c|c|c|c|c|c|}
\hline & \multicolumn{3}{|c|}{ Biatrial } & \multicolumn{3}{|c|}{ Left Atrial } & \multirow[b]{2}{*}{$P$ value } \\
\hline & $\begin{array}{l}\text { No. of } \\
\text { studies }\end{array}$ & $\begin{array}{c}\text { Total } \\
\text { sample } \\
\text { size }\end{array}$ & Mean $\pm S^{*}$ & $\begin{array}{l}\text { No. of } \\
\text { studies }\end{array}$ & $\begin{array}{c}\text { Total } \\
\text { sample } \\
\text { size }\end{array}$ & Mean $\pm S^{*}$ & \\
\hline \multicolumn{8}{|l|}{ Surgical subjects } \\
\hline 1-y survival & 32 & 2391 & $94.9 \pm 0.0$ & 20 & 1450 & $93.9 \pm 0.0$ & .999 \\
\hline 2-y survival & 14 & 1159 & $94.2 \pm 0.0$ & 4 & 154 & $92.8 \pm 0.0$ & .999 \\
\hline 3-y survival & 13 & 1136 & $92.8 \pm 0.0$ & 3 & 148 & $89.4 \pm 0.0$ & .500 \\
\hline 3-mo freedom from $A F$ & 23 & 1985 & $92.0 \pm 4.0$ & 16 & 757 & $86.1 \pm 8.4$ & .001 \\
\hline $1-y$ freedom from AF & 24 & 2260 & $88.9 \pm 8.2$ & 13 & 965 & $75.9 \pm 8.4$ & .001 \\
\hline $2-y$ freedom from AF & 15 & 1523 & $85.8 \pm 5.0$ & 6 & 216 & $74.5 \pm 1.9$ & .001 \\
\hline $3-y$ freedom from AF & 16 & 1684 & $87.1 \pm 4.7$ & 2 & 117 & $73.4 \pm 0.0$ & .001 \\
\hline \multicolumn{8}{|l|}{ Control subjects } \\
\hline 1-y survival & 9 & 378 & $97.9 \pm 0.0$ & 2 & 51 & $97.4 \pm 0.0$ & .999 \\
\hline 2-y survival & 5 & 299 & $97.7 \pm 0.0$ & - & - & - & - \\
\hline 3-y survival & 6 & 334 & $95.1 \pm 0.0$ & - & - & - & - \\
\hline 3-mo freedom from AF & 5 & 185 & $48.3 \pm 14.9$ & 2 & 51 & $43.2 \pm 24.2$ & .076 \\
\hline 1-y freedom from AF & 7 & 234 & $32.8 \pm 18.4$ & 3 & 78 & $26.8 \pm 21.5$ & .014 \\
\hline $2-y$ freedom from AF & 4 & 149 & $35.4 \pm 20.5$ & 1 & 32 & $66.2 \pm 0.0$ & .001 \\
\hline 3-y freedom from AF & 5 & 287 & $53.1 \pm 34.5$ & 1 & 227 & $78.8 \pm 0.0$ & .001 \\
\hline
\end{tabular}

$S D$, Standard deviation; $A F$, atrial fibrillation. *Sample weighted mean and corrected standard deviation.

nary veins as the source of the arrhythmia to a more complex pattern showing that pathophysiology is more complex and biatrial. $^{72,73}$

A better understanding for the possible reason for the differences in the mechanisms is important. Unfortunately, to some extent, our ability to do so is presently limited. In this study the results with the biatrial approach were superior to those achieved with left atrial ablation only. This might be related to the fact that the surgical patients usually presented with other cardiac pathologies, such as mitral valve and coronary artery disease, and with long duration of AF. As a result, the disease process in the surgical group of

TABLE 5. Average weighted reported postoperative survival and freedom from recurrent atrial fibrillation by temporal score

\begin{tabular}{|c|c|c|c|c|c|c|c|}
\hline & \multicolumn{3}{|c|}{ Prospective } & \multicolumn{3}{|c|}{ Retrospective } & \multirow[b]{2}{*}{$P$ value } \\
\hline & $\begin{array}{l}\text { No. of } \\
\text { studies }\end{array}$ & $\begin{array}{c}\text { Total } \\
\text { sample } \\
\text { size }\end{array}$ & Mean $\pm S D^{*}$ & $\begin{array}{l}\text { No. of } \\
\text { studies }\end{array}$ & $\begin{array}{c}\text { Total } \\
\text { sample } \\
\text { size }\end{array}$ & Mean \pm SD* $^{*}$ & \\
\hline \multicolumn{8}{|l|}{ Surgical subjects } \\
\hline 1-y survival & 13 & 560 & $95.2 \pm 0.0$ & 39 & 3281 & $94.3 \pm 0.0$ & .900 \\
\hline 2-y survival & 4 & 234 & $99.4 \pm 0.0$ & 14 & 1079 & $92.8 \pm 0.0$ & .003 \\
\hline 3-y survival & 2 & 157 & $96.1 \pm 0.0$ & 14 & 1127 & $91.9 \pm 0.0$ & .956 \\
\hline 3-mo freedom from AF & 10 & 459 & $86.3 \pm 4.4$ & 29 & 2283 & $91.4 \pm 5.8$ & .003 \\
\hline $1-y$ freedom from AF & 10 & 459 & $85.1 \pm 3.7$ & 27 & 2735 & $84.8 \pm 9.7$ & .375 \\
\hline $2-y$ freedom from AF & 10 & 459 & $70.1 \pm 5.7$ & 14 & 1395 & $85.2 \pm 5.3$ & .072 \\
\hline 3-y freedom from AF & 2 & 168 & $79.4 \pm 0.0$ & 16 & 1633 & $87.3 \pm 5.3$ & .095 \\
\hline \multicolumn{8}{|l|}{ Control subjects } \\
\hline 1-y survival & 7 & 217 & $96.5 \pm 0.0$ & 4 & 212 & $97.1 \pm 0.0$ & .990 \\
\hline 2-y survival & 1 & 87 & $100.0 \pm 0.0$ & 4 & 212 & $96.6 \pm 0.0$ & .995 \\
\hline 3-y survival & 1 & 87 & $100.0 \pm 0.0$ & 5 & 247 & $93.1 \pm 0.0$ & .995 \\
\hline 3-mo freedom from AF & 5 & 168 & $44.4 \pm 16.9$ & 2 & 68 & $54.9 \pm 15.6$ & .001 \\
\hline 1-y freedom from AF & 7 & 217 & $31.4 \pm 16.9$ & 3 & 95 & $30.0 \pm 23.5$ & .300 \\
\hline $2-y$ freedom from AF & 2 & 66 & $31.1 \pm 28.5$ & 3 & 115 & $44.2 \pm 15.2$ & .242 \\
\hline 3-y freedom from AF & 1 & 87 & $25.6 \pm 0.0$ & 5 & 427 & $71.3 \pm 27.7$ & .003 \\
\hline
\end{tabular}

$S D$, Standard deviation; $A F$, atrial fibrillation. *Sample weighted mean and corrected standard deviation. 
patients is much more advanced and diffuse when compared with that of patients treated with catheter pulmonary vein ablation for lone AF. Given that most mapping data for AF are based on nonsurgical patients with lone AF, it would be difficult to speculate about the exact mechanism among surgical patients to further support either surgical approach. Mapping during surgical intervention has the potential to guide surgeons to more specific ablation protocols. However, at this time, few clinical studies have assessed this strategy.

There are some reports documenting greater permanent pacemaker implantation after the maze procedure compared with that after left atrial ablation only. The indication for pacemaker use is sinus node dysfunction in most cases. The majority of patients with sinus node activity recover to the extent that patients are no longer pacemaker dependent. ${ }^{74}$ However, except for among patients after the maze I procedure, sinus node dysfunction cannot be attributed to the surgical procedure. It might be due to the fact that there is a higher success rate in ablating AF and that more cases of sick sinus syndrome that are strongly associated with AF are discovered.

Our study has several strengths and limitations. To our knowledge, this is the first attempt to systematically analyze published data for the surgical treatment of AF. We have conducted an extensive search for all clinical studies meeting our search criteria. However, publication bias might have eliminated potential studies for whatever reason deemed important by various editorial boards, and although there is no formal way to test for this, we would be remiss if we did not caution the readers of this potential for bias. In addition, determining rates of survival and freedom from postoperative AF was sometimes accomplished by viewing actual Kaplan-Meier curves and extrapolating results. This might have led to some discrepancies from the true published results. However, given the ease of reading a KaplanMeier plot, we think this is a minimal concern. Furthermore, our study included all studies relevant to our search strategy.

We made no attempt to exclude studies on the basis of size, degree of follow-up, or definition of AF. This might have biased our findings, but we have attempted to portray as general and inclusive a review of the literature as possible. The inclusion of different study groups might have biased the effects of any subgroup analysis, but we believe this effect could be minimal because of the consistent profile of patients referred for a surgical ablation procedure. Studies involving shorter follow-up might have ended before a return to dysrhythmia, thereby indicating artificially high rates of freedom from AF. Unfortunately, the traditional strengths of meta-analyses involving clinical trials are potential limitations for our study. Those meta-analyses have very defined patient groups from which a meta-analysis can be performed. There are few clinical trials involv- ing our subject matter, leaving us with retrospective trials from which patient groups were undoubtedly more heterogeneous. With this in mind, we have attempted to give the interested reader a composite view of the existing research regarding surgical treatment for AF.

We caution the reader that this is a summary of published results. We did not have access to original data, and thus errors might have occurred in our extrapolation of data from Kaplan-Meier tables, in the combination of multiple control groups into one group through weighting, and in the potential temporal bias of using data over an 11-year span. Surgical ablation expertise and technique have no doubt caused increases in both survival and freedom from $\mathrm{AF}$ rates. Furthermore, freedom from $\mathrm{AF}$ as a study end point was generally defined as a return to sinus rhythm, with no additional detail. It is possible that a different patient population would have provided different freedom from $\mathrm{AF}$ rates under different investigator protocols.

This summary review suggests the surgical treatment for AF offers similar postoperative survival rates and vastly superior freedom from AF rates compared with those of traditional therapies. In addition, the surgical treatment of AF involving biatrial status offers superior long-term survival and freedom from AF.

\section{References}

1. Halkos ME, Craver JM, Thourani VH, et al. Intraoperative radiofrequency ablation for the treatment of atrial fibrillation during concomitant cardiac surgery. Ann Thorac Surg. 2005;80:210-5.

2. Sueda T, Imai K, Orihashi K, et al. Midterm results of pulmonary vein isolation for the elimination of chronic atrial fibrillation. Ann Thorac Surg. 2005;79:521-5.

3. Gaynor SL, Schuessler RB, Baily MS, et al. Surgical treatment of atrial fibrillation: predictors of late recurrence. J Thorac Cardiovasc Surg. 2005;129:104-11.

4. Damiano RJ Jr, Gaynor SL, Bailey M, et al. The long-term outcome of patients with coronary disease and atrial fibrillation undergoing the Cox maze procedure. J Thorac Cardiovasc Surg. 2003;126:2016-21.

5. Prasad SM, Maniar HS, Camillo CJ, et al. The Cox maze III procedure for atrial fibrillation: long-term efficacy in patients undergoing lone versus concomitant procedures. J Thorac Cardiovasc Surg. 2003;126: 1822-8.

6. Fayad G, Le Tourneau T, Modine T, et al. Endocardial radiofrequency ablation during mitral valve surgery: effect on cardiac rhythm, atrial size, and function. Ann Thorac Surg. 2005;79:1505-11.

7. Ad N, Cox JL. The Maze procedure for the treatment of atrial fibrillation: a minimally invasive approach. J Card Surg. 2004;19:196-200.

8. Chen MC, Chang JP, Chang HW. Preoperative atrial size predicts the success of radiofrequency maze procedure for permanent atrial fibrillation in patients undergoing concomitant valvular surgery. Chest. 2004;125:2129-34.

9. Chiappini B, tin-Suarez S, LoForte A, et al. Cox/Maze III operation versus radiofrequency ablation for the surgical treatment of atrial fibrillation: a comparative study. Ann Thorac Surg. 2004;77:87-92.

10. de Lima GG, Kalil RA, Leiria TL, et al. Randomized study of surgery for patients with permanent atrial fibrillation as a result of mitral valve disease. Ann Thorac Surg. 2004;77:2089-94.

11. Knaut M, Tugtekin SM, Matschke K. Pulmonary vein isolation by microwave energy ablation in patients with permanent atrial fibrillation. J Card Surg. 2004;19:211-5. 
12. Mokadam NA, McCarthy PM, Gillinov AM, et al. A Prospective multicenter trial of bipolar radiofrequency ablation for atrial fibrillation: early results. Ann Thorac Surg. 2004;78:1665-70.

13. Romano MA, Bach DS, Pagani FD, et al. Atrial reduction plasty Cox maze procedure: extended indications for atrial fibrillation surgery. Ann Thorac Surg. 2004;77:1282-7.

14. Sie HT, Beukema WP, Elvan A, et al. Long-term results of irrigated radiofrequency modified maze procedure in 200 patients with concomitant cardiac surgery: six years experience. Ann Thorac Surg. 2004; 77:512-6.

15. Szalay ZA, Civelek A, Dill T, et al. Long-term follow-up after the mini-maze procedure. Ann Thorac Surg. 2004;77:1277-81.

16. Szalay ZA, Skwara W, Klovekorn WP, et al. Predictors of failure to cure atrial fibrillation with the mini-maze operation. J Card Surg. 2004;19:1-6.

17. Wisser W, Khazen C, Deviatko E, et al. Microwave and radiofrequency ablation yield similar success rates for treatment of chronic atrial fibrillation. Eur J Cardiothorac Surg. 2004;25:1011-7.

18. Akpinar B, Guden M, Sagbas E, et al. Combined radiofrequency modified maze and mitral valve procedure through a port access approach: early and mid-term results. Eur J Cardiothorac Surg. 2003; 24:223-30.

19. Colangelo N, Benussi S, Nascimbene S, et al. Cardiopulmonary bypass strategy during concomitant surgical treatment of mitral valve disease and atrial fibrillation. Perfusion. 2003;18:19-24.

20. Doll N, Kiaii BB, Fabricius AM, et al. Intraoperative left atrial ablation (for atrial fibrillation) using a new argon cryocatheter: early clinical experience. Ann Thorac Surg. 2003;76:1711-5.

21. Guden M, Akpinar B, Caynak B, et al. Left versus bi-atrial intraoperative saline-irrigated radiofrequency modified maze procedure for atrial fibrillation. Card Electrophysiol Rev. 2003;7:252-8.

22. Guden M, Akpinar B, Sagbas E, et al. A radiofrequency modified maze and valve procedure through a port-access approach. Heart Surg Forum. 2003;6:292-6.

23. Jessurun ER, van Hemel NM, Defauw JJ, et al. A randomized study of combining maze surgery for atrial fibrillation with mitral valve surgery. J Cardiovasc Surg (Torino). 2003;44:9-18.

24. Kondo N, Takahashi K, Minakawa M, et al. Left atrial maze procedure: a useful addition to other corrective operations. Ann Thorac Surg. 2003;75:1490-4.

25. Lee JW, Park NH, Choo SJ, et al. Surgical outcome of the maze procedure for atrial fibrillation in mitral valve disease: rheumatic versus degenerative. Ann Thorac Surg. 2003;75:57-61.

26. Mantovan R, Raviele A, Buja G, et al. Left atrial radiofrequency ablation during cardiac surgery in patients with atrial fibrillation. J Cardiovasc Electrophysiol. 2003;14:1289-95.

27. Raman J, Ishikawa S, Storer MM, et al. Surgical radiofrequency ablation of both atria for atrial fibrillation: results of a multicenter trial. J Thorac Cardiovasc Surg. 2003;126:1357-66.

28. Raman JS, Ishikawa S, Power JM. Epicardial radiofrequency ablation of both atria in the treatment of atrial fibrillation: experience in patients. Ann Thorac Surg. 2002;74:1506-9.

29. Schuetz A, Schulze CJ, Sarvanakis KK, et al. Surgical treatment of permanent atrial fibrillation using microwave energy ablation: a prospective randomized clinical trial. Eur J Cardiothorac Surg. 2003;24: 475-80.

30. Starck C, Botha CA, Roser D, et al. Results of a modified left atrial maze procedure as a combined procedure. Thorac Cardiovasc Surg. 2003;51:147-53.

31. Ad N, Cox JL. Combined mitral valve surgery and the Maze III procedure. Semin Thorac Cardiovasc Surg. 2002;14:206-9.

32. Deneke T, Khargi K, Grewe PH, et al. Left atrial versus bi-atrial maze operation using intraoperatively cooled-tip radiofrequency ablation in patients undergoing open-heart surgery: safety and efficacy. J Am Coll Cardiol. 2002;39:1644-50.

33. Guden M, Akpinar B, Sanisoglu I, et al. Intraoperative saline-irrigated radiofrequency modified Maze procedure for atrial fibrillation. Ann Thorac Surg. 2002;74(suppl):S1301-6.

34. Guang Y, Zhen-jie C, Yong LW, et al. Evaluation of clinical treatment of atrial fibrillation associated with rheumatic mitral valve disease by radiofrequency ablation. Eur J Cardiothorac Surg. 2002;21:249-54.
35. Knaut M, Tugtekin SM, Spitzer S, Gulielmos V. Combined atrial fibrillation and mitral valve surgery using microwave technology. Semin Thorac Cardiovasc Surg. 2002;14:226-31.

36. Kobayashi J, Sasako Y, Bando K, et al. Eight-year experience of combined valve repair for mitral regurgitation and maze procedure. J Heart Valve Dis. 2002;11:165-71.

37. Kress DC, Sra J, Krum D, et al. Radiofrequency ablation of atrial fibrillation during mitral valve surgery. Semin Thorac Cardiovasc Surg. 2002;14:210-8.

38. Maessen JG, Nijs JF, Smeets JL, Vainer J, Mochtar B. Beating-heart surgical treatment of atrial fibrillation with microwave ablation. Ann Thorac Surg. 2002;74(suppl):S1307-11.

39. Mohr FW, Fabricius AM, Falk V, et al. Curative treatment of atrial fibrillation with intraoperative radiofrequency ablation: short-term and midterm results. J Thorac Cardiovasc Surg. 2002;123:919-27.

40. Nakajima H, Kobayashi J, Bando K, et al. The effect of cryo-maze procedure on early and intermediate term outcome in mitral valve disease: case matched study. Circulation. 2002;106(suppl 1):I46-50.

41. Ngodngamthaweesuk M, Boonkasem S, Subhannachart W, et al. Modified Cox maze procedure for atrial fibrillation with mitral valve diseases. J Med Assoc Thai. 2002;85:1182-8.

42. Ruchat P, Schlaepfer J, Delabays A, et al. Left atrial radiofrequency compartmentalization for chronic atrial fibrillation during heart surgery. Thorac Cardiovasc Surg. 2002;50:155-9.

43. Tanaka H, Narisawa T, Mori T, et al. Pulmonary vein isolation for chronic atrial fibrillation associated with mitral valve disease: the midterm results. Ann Thorac Cardiovasc Surg. 2002;8:88-91.

44. Wellens F, Casselman F, Geelen P, et al. Combined atrial fibrillation and mitral valve surgery using radiofrequency technology. Semin Thorac Cardiovasc Surg. 2002;14:219-25.

45. Khargi K, Deneke T, Haardt H, et al. Saline-irrigated, cooled-tip radiofrequency ablation is an effective technique to perform the maze procedure. Ann Thorac Surg. 2001;72(suppl):S1090-5.

46. Kim KB, Huh JH, Kang CH, et al. Modifications of the Cox-Maze III procedure. Ann Thorac Surg. 2001;71:816-22.

47. Isobe $\mathrm{F}$, Kumano $\mathrm{H}$, Ishikawa $\mathrm{T}$, et al. A new procedure for chronic atrial fibrillation: bilateral appendage-preserving maze procedure. Ann Thorac Surg. 2001;72:1473-8.

48. Pasic M, Bergs P, Muller P, et al. Intraoperative radiofrequency maze ablation for atrial fibrillation: the Berlin modification. Ann Thorac Surg. 2001;72:1484-90.

49. Raanani E, Albage A, David TE, et al. The efficacy of the Cox/maze procedure combined with mitral valve surgery: a matched control study. Eur J Cardiothorac Surg. 2001;19:438-42.

50. Raman JS, Seevanayagam S, Storer M, et al. Combined endocardial and epicardial radiofrequency ablation of right and left atria in the treatment of atrial fibrillation. Ann Thorac Surg. 2001;72(suppl): S1096-9.

51. Sie HT, Beukema WP, Misier AR, et al. Radiofrequency modified maze in patients with atrial fibrillation undergoing concomitant cardiac surgery. J Thorac Cardiovasc Surg. 2001;122:249-56.

52. Williams MR, Stewart JR, Bolling SF, et al. Surgical treatment of atrial fibrillation using radiofrequency energy. Ann Thorac Surg. 2001; 71:1939-43.

53. Arcidi JM Jr, Doty DB, Millar RC. The Maze procedure: the LDS Hospital experience. Semin Thorac Cardiovasc Surg. 2000;12:38-43.

54. Gaita F, Gallotti R, Calo L, et al. Limited posterior left atrial cryoablation in patients with chronic atrial fibrillation undergoing valvular heart surgery. J Am Coll Cardiol. 2000;36:159-66.

55. Izumoto $\mathrm{H}$, Kawazoe K, Eishi K, et al. Medium-term results after the modified Cox/Maze procedure combined with other cardiac surgery. Eur J Cardiothorac Surg. 2000;17:25-9.

56. Jatene MB, Cial MB, Tarasoutchi $\mathrm{F}$, et al. Influence of the maze procedure on the treatment of rheumatic atrial fibrillation-evaluation of rhythm control and clinical outcome in a comparative study. Eur J Cardiothorac Surg. 2000;17:117-24.

57. Jessurun ER, van Hemel NM, Defauw JA, et al. Results of maze surgery for lone paroxysmal atrial fibrillation. Circulation. 2000;101:1559-67.

58. McCarthy PM, Gillinov AM, Castle L, Chung M, Cosgrove Dl. The Cox-Maze procedure: the Cleveland Clinic experience. Semin Thorac Cardiovasc Surg. 2000;12:25-9. 
59. Schaff HV, Dearani JA, Daly RC, Orszulak TA, Danielson GK. Cox-Maze procedure for atrial fibrillation: Mayo clinic experience. Semin Thorac Cardiovasc Surg. 2000;12:30-7.

60. Tuinenburg AE, Van Gelder IC, Tieleman RG, et al. Mini-maze suffices as adjunct to mitral valve surgery in patients with preoperative atrial fibrillation. J Cardiovasc Electrophysiol. 2000;11:960-7.

61. Handa N, Schaff HV, Morris JJ, et al. Outcome of valve repair and the Cox maze procedure for mitral regurgitation and associated atrial fibrillation. J Thorac Cardiovasc Surg. 1999;118:628-35.

62. Kalil RA, Albrecht A, Lima GG, et al. Results of the surgical treatment of chronic atrial fibrillation. Arq Bras Cardiol. 1999;73:139-48.

63. Kim KB, Cho KR, Sohn DW, et al. The Cox-Maze III procedure for atrial fibrillation associated with rheumatic mitral valve disease. Ann Thorac Surg. 1999;68:799-803.

64. Nitta T, Ishii Y, Ogasawara H, et al. Initial experience with the radial incision approach for atrial fibrillation. Ann Thorac Surg. 1999;68:805-10.

65. Szalay ZA, Skwara W, Pitschner HF, et al. Midterm results after the Mini-Maze procedure. Eur J Cardiothorac Surg. 1999;16:306-11.

66. Izumoto H, Kawazoe K, Kitahara H, Kamata J. Operative results after the Cox/maze procedure combined with a mitral valve operation. Ann Thorac Surg. 1998;66:800-4.
67. Cox JL, Schuessler RB, Lappas DG, Boineau JP. An 8 1/2-year clinical experience with surgery for atrial fibrillation. Ann Surg. 1996;224:267-73.

68. Vigano M, Graffigna A, Ressia L, et al. Surgery for atrial fibrillation. Eur J Cardiothorac Surg. 1996;10:490-7.

69. Gregori F Jr, Cordeiro CO, Couto WJ, et al. Cox maze operation without cryoablation for the treatment of chronic atrial fibrillation. Ann Thorac Surg. 1995;60:361-3.

70. Cohen J. Statistical power analysis for the behavioral sciences. 2nd ed. Hillsdale, NJ: Erlbaum; 1988.

71. Hunter JE, Schmidt FL. Methods of meta-analysis: correcting error and bias in research findings. Newbury Park (CA): Sage;1990.

72. Haissaguerre M, Jais P, Shah DC, et al. Spontaneous initiation of atrial fibrillation by ectopic beats originating in the pulmonary veins. $N$ Engl J Med. 1998;339:659-66.

73. Nademanee K, McKenzie J, Kosar E, et al. A new approach for catheter ablation of atrial fibrillation: mapping of the electrophysiologic substrate. J Am Coll Cardiol. 2004;43:2044-53.

74. Pasic M, Musci M, Siniawski H, Edelmann B, Tedoriya T, Hetzer R. Transient sinus node dysfunction after the Cox-maze III procedure in patients with organic heart disease and chronic fixed atrial fibrillation. J Am Coll Cardiol. 1998;32:1040-7.

\section{ON THE MOVE?}

Don't miss a single issue of the journal! To ensure prompt service when you change your address, please photocopy and complete the form below.

Please send your change of address notification at least six weeks before your move to ensure continued service. We regret we cannot guarantee replacement of issues missed due to late notification.

\section{JOURNAL TITLE:}

Fill in the title of the journal here.

\section{OLD ADDRESS:}

Affix the address label from a recent issue of the journal here.

\section{NEW ADDRESS:}

Clearly print your new address here.

Name

Address

City/State/ZIP
COPY AND MAIL THIS FORM TO:

Elsevier Inc.

Subscription Customer Service

6277 Sea Harbor Dr

Orlando, FL 32887
OR FAX TO:

407-363-9661

OR E-mail:

elspcs@elsevier.com
OR PHONE:

800-654-2452

Outside the U.S., call

407-345-4000 